\title{
Commentary on Sims et al. (2012): A timely response to the impact of smoke-free public places on the most exposed children
}

It is now well established that legislation prohibiting smoking in public places is effective in reducing secondhand smoke (SHS) exposure [1-3]. Nonetheless, in the face of arguments that introducing smoke-free public places would increase smoking in the home, Sims et al. [4] provide timely evidence that smoke-free legislation does not displace adult smoking to the home, but rather reduces SHS exposure among most at risk children, i.e. those with smoking parents or living in homes allowing smoking. These findings dispute the arguments and inform health advocates and policymakers about the unintended health benefits of protecting non-smokers, especially children exposed to second-hand smoke in the home [5]. Given that the main source of SHS exposure among children is domestic [6,7], the reported declines reflect changing social norms around smoking [8], perhaps derived from voluntary family-based restrictions by adults to promote health in children [6].

Children are particularly vulnerable to SHS exposure, as even modest levels of exposure have been associated with respiratory abnormalities and other adverse health effects $[9,10]$. As adolescents observe smoking in the domestic setting, they tend more towards seeing smoking as normal adult behaviour, and attribute favourable outcome expectations over time with repeated exposure $[8,11]$. Research has shown that adolescent adoption of smoking is related to perceptions of significant others, such as parental smoking behaviour, as well as societal norms of smoking [12,13]. In an environment where a non-smoking directive, e.g. smoke-free homes or cars, is enacted children will possibly perceive smoking as a socially unacceptable behaviour, and may be less likely to take up smoking [14]. However, despite reported declines in SHS exposure by the authors, the high levels of children's exposure in England (approximately half living in homes allowing smoking and a third with smoking parents) may send an unequivocal message to youths that smoking is still a normative behaviour, and might sensitize them to start smoking.

Sims et al.'s work therefore underlines the importance of continuing to undertake interventions and legislated policies to make smoke-free environments, especially in homes and cars, the societal norm. Such efforts should include community-level campaigns and programmes to raise awareness of the damaging effects of SHS exposure and support adults, particularly those living in smoking homes, to enforce smoke-free policies voluntarily in their homes and cars. The balance of evidence from several studies suggests strongly that the primary objective of reducing second-hand smoke exposure has been achieved, particularly among non-smokers in workplaces and the hospitality industry [15-17]. Nonetheless, to the extent that smoking in domestic settings remains evident in several jurisdictions [1], there is the need to encourage governments to enact policies that will make smoke-free homes the accepted norm.

Further research is therefore required to inform future smoke-free policy development by exploring how these voluntary and legislated policies are implemented, and how they work to impact upon young children living in smoking and non-smoking households. Finally, as studies on the long-term effect of smoke-free policies on children's second-hand smoke exposure are mixed, more research is needed to examine population-level changes in SHS exposure in the long term among these groups, as well as whether there are any significant changes in their health after enactment of smoke-free legislation.

\section{Declaration of interests}

None.

Keywords Children, legislation, second-hand smoke, smoke-free, smoking norms, youth smoking.

ABRAHAM BROWN

Centre for Tobacco Control Research, UK Centre for Tobacco Control Studies, Institute for Social Marketing, University of Stirling, Stirling FK9 4LA, UK. E-mail:a.k.brown@stir.ac.uk

\section{References}

1. Callinan J. E., Clarke A., Doherty K., Kelleher C. Legislative smoking bans for reducing secondhand smoke exposure, smoking prevalence and tobacco consumption. Cochrane Database Syst Rev 2010; 4. CD005992. doi: 10.1002/ 14651858 .

2. Akhtar P. C., Haw S. J., Levin K. A., Currie D. B., Zachary R., Currie C. E. Socioeconomic differences in second-hand smoke exposure among children in Scotland after introduction of the smoke-free legislation. J Epidemiol Commun Health 2010; 64: 341-6.

3. Allwright S., Paul G., Greiner B., Mullally B. J., Pursell L., Kelly A. et al. Legislation for smoke-free workplaces and health of bar workers in Ireland: before and after study. BMJ 2005; 331: 1117-20.

4. Sims M., Bauld L., Gilmore A. England's legislation on smoking in indoor public places and work-places: impact on the most exposed children. Addiction 2012; 107: 2009-16.

5. Akhtar P. C., Currie D. B., Currie C. E., Haw S. J. Changes in Child Exposure to Environmental Tobacco Smoke (CHETS) 
study after implementation of smoke-free legislation in Scotland: national cross sectional survey. BMJ 2007; 335: 545-9.

6. O'Dowd A. Smoking ban in public places also cuts smoking at home. BMJ 2005; 331: 129.

7. Jarvis M. J., Mindell J., Gilmore A., Feyerbrand C., West R. Smoke-free homes in England: prevalence, trends and validation by cotinine in children. Tob Control 2009; 18: 491-5.

8. Moore G. F., Holliday J. C., Moore L. A. R. Socioeconomic patterning in changes in child exposure to secondhand smoke after implementation of smoke-free legislation in Wales. Nicotine Tob Res 2011; 13: 903-10.

9. Pattenden S., Antova T., Neuberger M., Nikiforov B., De Sario M., Grize L. et al. Parental smoking and children's respiratory health: independent effects of prenatal and postnatal exposure. Tob Control 2006; 15: 294-301.

10. Vork K. L., Broadwin R. L., Blaisdell R. J. Developing asthma in childhood from exposure to secondhand tobacco smoke: insights from a meta-regression. Environ Health Perspect 2007; 115: 1394-400.

11. Alesci N. L., Forster J. L., Blaine T. Smoking visibility, perceived acceptability, and frequency in various locations among youth and adults. Prev Med 2003; 36: 272-81.
12. Wiium N., Torsheim T., Wold B. Normative processes and adolescents' smoking behaviour in Norway: a multilevel analysis. Soc Sci Med 2006; 62: 1810-8.

13. Cialdini R. B., Trost M. R. Social influence: social norms, conformity, and compliance. In: Gilbert D. T., Fiske S. T., Lindzey G., editors. The Handbook of Social Psychology. Boston: McGraw-Hill; 1998, p. 151-92.

14. Wakefield M. A., Chaloupka F. J., Kaufman N. T., Orleans C. T., Barker D. C., Ruel E. E. Effect of restrictions at home, at school, and in public places on teenage smoking: cross sectional study. BMJ 2000; 321: 333-7.

15. Semple S., Creely K. S., Naji A., Miller B. J., Ayres J. G. Secondhand smoke levels in Scottish pubs: the effect of the smoke-free legislation. Tob Control 2007; 16: 12732.

16. Pickett M., Schober S. E., Brody D. J., Curtin L. R., Giovino G. A. Smoke-free laws and secondhand smoke exposure in US non-smoking adults, 1999-2002. Tob Control 2006; 15: 302-7.

17. Abrams S. M., Mahoney M. C., Hyland A., Cummings K. M., Davis W., Song L. Early evidence on the effectiveness of clean indoor air legislation in New York State. Am J Public Health 2006; 96: 296-8. 